\title{
cDNA Cloning and Expression Analysis of Mest Gene in the Bufo gargarizans
}

\author{
WANG Jing-jing, NIE Liu-wang ", JIA Rui, WANG Ning \\ (The Provincial Key Laboratory of the Conservation and Exploitation Research of Biological Resources in Anhui, College of Life \\ Sciences, Anhui Normal University, Wuhu 241000, China)
}

\begin{abstract}
The Mest (mesoderm-specific transcript) gene has been considered an imprinting gene in human and mouse, and was also confirmed in other mammals and flowering plants. To investigate the function and evolution of this gene, the cDNA of full length Mest gene was obtained using 5'- and 3'-RACE from the Chinese Large Toad (Bufo gargarizans). The transcript is $1325 \mathrm{bp}$ in length which contains a complete open reading frame (ORF) encoding a polypeptide of 326 amino acids (GenBank accession number: ABQ10905). There is a typical $\alpha / \beta$ hydrolase fold domain in the putative gene product, and it shows high similarity to sequence of homologous protein of Xenopus tropicali (86\%), mammlian $(70 \%-80 \%)$. RT-PCR (reverse transcriptase-polymerase chain reaction) analysis demonstrated that the Bufo gargarizans Mest (BgMest) gene is expressed widely in testis, ovary, liver, kidney, spleen, brain, stomach and lung. The conservation of the BgMest gene sequences, protein secondary structure of the BgMest protein, in addition to the expression pattern of the BgMest gene, suggested that the function of BgMest was conserved in amphibians. However, the phylogenetic tree of the imprinting gene of the mammals and other vertebrates examined in this study indicated their divergent origins.
\end{abstract}

Key words: Bufo gargarizans; Mest gene; Imprinting gene; RACE; RT-PCR

\section{中华大蟾蜍 Mest 基因的 cDNA 克隆和表达分析}

\author{
王晶晶, 聂刘旺 ${ }^{*}$, 贾 瑞, 汪 宁 \\ （安徽师范大学 生命科学学院, 安徽重要生物资源保护与利用研究重点实验室, 安徽 芜湖 241000)
}

\begin{abstract}
摘要：Mest 基因是一种印记基因，在人、小鼠以及其他的哺乳动物和有花植物中都有研究报道。为了更好地 研究该基因的功能和进化特点, 利用 RACE 法获得了中华大蟾蜍 Mest 基因 (BgMest) 的 cDNA 全长序列(1325bp), 它包含一个完整的 ORF，可编码 326 个氨基酸的多肽（GenBank 登陆号：ABQ10905）。多肽链中包含一个典型的 $\alpha / \beta$ 水解酶折叠结构域, 其在氨基酸水平上与热带爪蟾和一些哺乳动物分别存在 $86 \%$ 和 $70 \% \sim 80 \%$ 的相似性。进化 树分析显示 Mest 基因为单系起源。RT-PCR 显示, BgMest 基因在精巢、卵巢、肝、肾、脑、胃和肺中都有表达, 并且该基因在序列、表达模式以及蛋白产物的高级结构的高度保守性都说明它在两栖类生物中是保守的。但是在 对哺乳动物以及一些脊椎动物的印记基因进行进化分析时, 发现它们具有不同的起源。
\end{abstract}

关键词: 中华大蟾蜍; Mest 基因; 印记基因; RACE; RT-PCR

中图分类号: Q959.53; Q951.3; Q349; Q78 文献标识码: A 文章编号: 0254-5853-(2009)04-0369-08

Genomic imprinting refers to the parent-of-origin specific gene modification resulting in monoallelic expression of a gene dependent on its parental origin (Brannan \& Bartolomei, 1999). The molecular mechanism of genomic imprinting appears to share aspects of epigenetic regulation with $\mathrm{X}$ inactivation in human and mouse, since both phenomena involve DNA methylation and asynchronous replication of DNA (Saitoh \& Wada, 2000). This phenomenon has been also observed in mammals and flowering plants (Scott \&

Received date: 2009-02-24; Accepted date: 2009-05-27

Foundation items: Supported by the National Natural Science Foundation of China (No.30770296); the Natural and Science Key Project of Anhui Educational Department (KJ2007A022); the Key Lab Project of Biotic Environment and Ecology Safety in Anhui Province (2006)

收稿日期：2009-02-24; 接受日期：2009-05-27

*通讯作者 (Corresponding author), Tel: +865533869571, Fax:+865533869571, E-mail: 1wnie@mail.ahnu.edu.cn 
Spielman,2004). To date, there are approximately 100200 imprinting gens in the mammal genome, such as H19, IGF2, IGF2R, XIST, etc...(Looijenga et al, 1997). These special genes in mammals are imprinted so that only one of the parental alleles is actually expressed in target cells. Mest (mesoderm-specific transcript)/Peg1 (paternally expressed gene 1) is an important maternally imprinted mammalian gene which is predominantly expressed in the mesoderm and its derivatives (Reule et al, 1998; Isles et al, 2006). Only the paternal copy of the gene is expressed in interspecific hybrids. This gene has been assigned to $7 \mathrm{q} 32$ in human and mapped to chromosome 6 in mouse (Lefebvre et al,1997; Kosaki et al,2000)

The Mest orthologs were studied mainly in mammals, but there were also reports in non-mammalian species like pufferfish (Fugu rubripes), zebrafish, Xenopus tropicalis and tammar wallaby (Suzuki et al, 2005). The widespread Bufo gargarizans is a representative of Bufonidae, Anura, Amphbia, and it plays an important role in the ecological balance of nature. The amphibians represent a bridge in the evolution of vertebrates from aquatic to terrestrial. They have highly specialized morphological and functional characteristics to adapt to different environments. In this paper, we isolated and analyzed the expression pattern of BgMest. To understand the function and evolution of this gene, the phylogenic tree was also constructed.

\section{Materials and Methods}

\subsection{Animals}

Two male and two female adult B. gargarizans were obtained from the suburb of Wuhu city, Anhui province, China. Tissue from the testis, ovary, liver, kidney, spleen, brain, stomach and lung were dissected from the toads. Samples were snap frozen in liquid nitrogen, and stored at $-80^{\circ} \mathrm{C}$ until use.

\subsection{Cloning of Mest cDNA}

To amplify the conservative fragment of BgMest cDNA (424bp), a pair of primers (M1: GATTGCCCTGGACTTTAT, M2: TACACCTGTCGGGAGTCC) were designed according to the conserved amino acid sequences that have been found in human (Accession number: NP_803490), and mouse (Accession number: AAM78507). To obtain the complete BgMest cDNA, rapid amplification of cDNA ends (RACE) technique was performed (Invitrogen, Tokyo, Japan) according to instructions.

Total RNA was extracted from toad testis with
TRIzol (Invitrogen) according to the manufacturer provided protocol. Single-stranded cDNA was prepared with SuperScript TM III reverse transcriptase, following the operating instruction. For the 3'-RACE, M1 and anchor primers (5'-CGTCTAGAGGTACCGGATCCAACA-3') were used. The PCR reaction consisted of 30 cycles of $95^{\circ} \mathrm{C}(30 \mathrm{~s}), 65^{\circ} \mathrm{C}(30 \mathrm{~s})$ and $72^{\circ} \mathrm{C}(3 \mathrm{~min})$, ending with a $7 \mathrm{~min}$ extension step at $72^{\circ} \mathrm{C}$. After cDNA fragments had been obtained by 3'-RACE, they were inserted into the PCR2.1 vector and sequenced. For the 5 '-RACE, single-stranded (ss) cDNA was reverse-transcribed from total RNA according to the manufacturer's protocol (Invitrogen, Tokyo, Japan). Oligo dA was added to the ss cDNA by terminate deoxynucleotidyl transferase according to the protocol (TOYOBO, Tokyo, Japan), which used as a template for the PCR. The PCR was performed by using M2 and oligo dT anchor (5'-CGTCTAGAGGTACCGGATCCAACAT(17)V-3') primers for 30 cycles under the following conditions: denaturation at $95^{\circ} \mathrm{C}$ for $30 \mathrm{~s}$, annealing at $65^{\circ} \mathrm{C}$ for $30 \mathrm{~s}$, extension at $72^{\circ} \mathrm{C}$ for $2 \mathrm{~min}$, and ending with an extension step at $72^{\circ} \mathrm{C}$ for $7 \mathrm{~min}$. After cDNA fragments had been obtained by this procedure, they were inserted into the PCR2.1 vector and sequenced.

\subsection{RT-PCR analysis and tissue expression of Mest gene}

To analyze the tissue specificity of Mest gene expression, total RNA was extracted from several tissues including testis, ovary, liver, kidney, spleen, brain, stomach, lung of male and female specimens. It was prepared for homogenizing the tissue in $100 \mathrm{uL}$ Trizol reagent (Takara, China) and $50 \mathrm{uL}$ chloroform. The aqueous phase was precipitated in $150 \mathrm{uL}$ isopropanol at $4{ }^{\circ} \mathrm{C}$ overnight. The RNA pellet was rinsed in $75 \%$ ethanol and resuspended in $12 \mathrm{uL}$ DEPC-treated $\mathrm{ddH}_{2} \mathrm{O}$ and immediately used for RT-PCR. Reverse transcriptase polymerase chain reaction (RT-PCR) amplifications were performed using two degenerated primers (M1 and M2) The nucleotide sequences of the primers used were EFI $\alpha$, H1: TCCACCACCACCGGCCACCT; H2:CTCCCACACCAGCAGCAACAAT.

RT-PCR was carried out using $3 \mathrm{uL}$ total RNA per reaction, $1 \times$ buffer reaction $\operatorname{mix}$ and $0.2 \mu \mathrm{mol} / \mathrm{L}$ b-actin primers or $0.3 \mu \mathrm{mol} / \mathrm{L}$ of Mest primers in separate tubes, in a total volume of $20 \mu \mathrm{L}$. All reactions for Mest contained 6\% DMSO. cDNA synthesis was performed at $50^{\circ} \mathrm{C}$ for $30 \mathrm{~min}$ and amplification conditions were: $94^{\circ} \mathrm{C}$ 15 min for initial denaturation; $94^{\circ} \mathrm{C} / 30$ s for denaturation, 
$56^{\circ} \mathrm{C} / 60 \mathrm{~s}$ for annealing, $72^{\circ} \mathrm{C} / 60 \mathrm{~s}$ for extension, 35 cycles; $72{ }^{\circ} \mathrm{C} / 10 \mathrm{~min}$ for final extension. Each PCR product was detected by electrophoresis on $1.2 \%$ agarose gel.

\subsection{DNA sequencing and bioinformatical analysis}

Homology analysis of the amino acid sequence alignments of BgMest and other vertebrates including Homo species (Accession number: NP_803490), Mus musculus (Accession number: AAM78507), Macaca mulatta (Accession number: XP_001098320), Gallus gallus (Accession number: XP_425258), Xenopus tropicalis (Accession number: NP_001005789), Takifugu rubripes (CAB96533), and Danio rerio (Accession number: CAK04921) was performed with Clustal X1.81 software. Phylogenetic tree construction was achieved using MEGA V2.1 (Molecular Evolutionary Genetic Analysis) program of neighbour-joining (NJ) methods. Analysis of protein secondary structure was finished by predictprotein program.

\section{Results}

\subsection{Sequence analysis of $\mathrm{Bg}$ Mest gene}

To isolate the BgMest, the complete cDNA were amplified by 5 ' and 3'-RACE technique, a 1325 bp Mest cDNA encoding a predicted protein of 336 amino acids was obtained. The cDNA sequence included 34 nucleotide acids in 5'-UTR, 310 nucleotide acids in 3'-UTR, and a complete open reading frame (ORF) which conformed to several characteristics that GC content of cDNA sequence is high but the sequence is short in 5'-UTR. Fig.1 showed the full-length Mest cDNA of B. gargarizans. This BgMest sequence was determined by comparison with orthologous proteins of the amino acid sequences using BLAST (Accession number is ABQ10905 in the NCBI database).

The putative amino acid sequences of BgMest were aligned with orthologous proteins from Homo species, Mus musculus, Macaca mulatta, Gallus gallus, Xenopus tropicalis, Takifugu rubripes and Danio rerio. The BgMest showed a significant sequence homology with those of other vertebrate Mest proteins. It exhibited the highest similarity to Xenopus tropicalis Mest (86\% identities) and the BgMest is similar to other vertebrates with $70 \%-80 \%$ nt identities (Fig.2).

Additionally, based on amino acid sequence of the Mest protein, they contained a conserved domain named $\alpha / \beta$-hydrolase fold domain. It conformed to the 3 -D model of the Mest protein (Fig. 3). According to analysis via Phyre program, the model belonged to the $\alpha / \beta$-hydrolase family. Fig. 2 showed that this domain was located at amino position $88-320$ in mammal, at $105-$ 337 in zerbrafish and at $64-296$ in Gallus gallus. The domain of BgMest protein was located at position $107-$ 321. This conserved domain was determined to be prominently expressed in mesodermal derivatives during embryogenesis only from the paternally inherited allele, and was detected in a number of proteins of several animals, plants and microorganism (Kamei et al, 2007; Yun et al, 2002).

Analysis of protein secondary structure (Fig. 4) and 3-D model of BgMest protein can understand its function and recognize the interactions within proteins, which is important in biological and medical research. Protein secondary structure of BgMest gene is composed of helix (h), strand (s) and coil (c) like the Mest gene of mammals. It includes six helixes, six strands and sixteen coils within the BgMest protein (Fig. 4). It was shown that the BgMest protein also contains a conserved $\alpha / \beta$-hydrolase fold domain by analysis 3-D model of BgMest protein (Fig.3).

\subsection{Phylogenetic tree of Mest gene}

The relationships between the proteins encoded by BgMest gene and the corresponding proteins from other species were analyzed using neighbour-joining (NJ) method (Fig. 5). The tree showed that all mammalian proteins cluster together and the fish and amphibian cluster into another branch. This may suggest the divergent origins separating mammalians from the other vertebrates including teleosts, avian and amphibians. Mycobacterium tuberculosis $C$ belonged to an actinomyces, which was separated from the vertebrate. The results were identical with traditional classification, which supports the Mest protein monophyly.

\subsection{Expression of $\mathbf{B g}$ Mest}

To determine the multiple tissue expression of this gene, RT-PCR was carried out on various tissues (including testis, ovary, liver, kidney, spleen, brain, stomach and lung) in adult B. gargarizans. As a control, cytoplasmic EFI-a gene from $B$. gargarizans was used. As seen in Fig. 6, all the aforementioned tissues were expressed.

\section{Discussion}

The genomic structure of Mest gene has been shown to include a $\mathrm{C}_{\mathrm{P}} \mathrm{G}$ island in human, mouse and zerbrafish (Reule et al, 1998; Kosaki et al, 2000; Hahn et al, 2005). A characteristic of imprinted genes is that maternal and paternal alleles show differences in methylation position 
GAATGGTGGATTCAGGTGGGGCTGATTACTGTGCCTCTGCTTGCTGTATAC

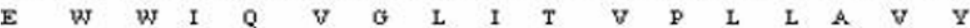
CTGCACATTCCTCCAOCTAACCTCTCCOCAGCACTGTTCACA TGGAGGTCA $\begin{array}{lllllllllllllllll}\text { L } & \text { H } & \text { I } & \text { P } & \text { P } & \text { p } & \text { N } & \text { L } & S & \text { p } & \text { A } & \text { L } & \text { F } & \text { T } & \text { W } & R & S\end{array}$ TTTGGCGCATTTTTCACATTCCAAGAACAGCATATCTTTTATAGAGAATCT

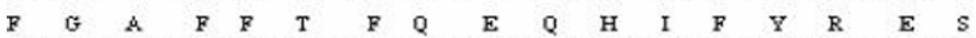
TGGGGAGCTGTGGGAAGCTCAGATGTGGTTATTATTTACATGGATTCCCG

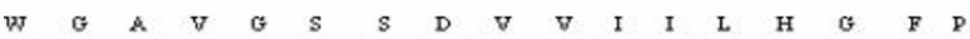
ACATCAAGCTACGACTGGTACAAGATCTGGGAAGGGCTAACACAAAGATTT 295

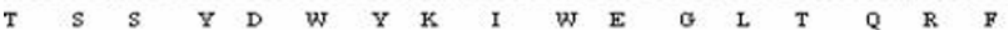
CAAAGAGTGATTGOCCTGGACTTTATAGGCTTTGGTTTTAGTGACAAGCCA

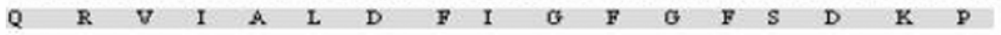
AGATTCCAOCGCTATTCCATTTTTGAGCAGGCCAGTATCGTGGAAGCACTG

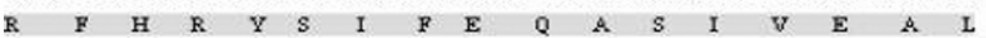
ATCAGTCAOCTTGGCTTAACAGATCAAAAAGTGAACTTACTTTCTCATGAT $\begin{array}{lllllllllllllllll}I & S & H & L & G & L & T & D & Q & K & V & N & L & L & S & H & D\end{array}$ TA TGGAGA TACTGTOGCCCAGGAATTGCTTTA TAGGTATGAACAOCAAAGA $\begin{array}{lllllllllllllllll}Y & G & D & T & V & A & Q & E & L & L & Y & R & Y & E & H & Q & R\end{array}$ CAAGGACATATTAACA TCGGTAGTTTGTGTCTCTCCAATGGAGGAATCTTC

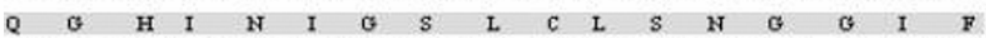
CCAGAGACACATCACCCCAGATTAATTCAGAAGCTGCTGAAAGATGGTGGG 601 $\begin{array}{lllllllllllllllll}P & E & T & H & H & P & R & L & I & Q & K & L & L & K & D & G & G\end{array}$ ATTTTTTCACCAATACTAACTAGACTGATGAACTTTTACTTCTTTAGCAAA $\begin{array}{lllllllllllllllll}I & F & S & P & I & L & T & R & L & M & N & F & Y & F & F & S & K\end{array}$ GGTATCGGTGAGGTATTTGGACCTTATACTCAGCCTTCAGACACTGAATAC 703

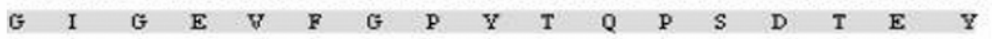
TGGGATATGTGGACAGCCCTCAGGATCAACGATGGCAATCTAGTAGTAGAC 754

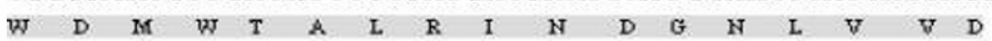
AGTATTTTACAGTATATAAACCAGCGCAGAAAGTACAGAGAAOGCTGGGTG 805 $\begin{array}{llllllllllllllllll}S & I & I & Q & Y & I & N & Q & R & R & K & Y & R & E & R & W & V\end{array}$ GGAGCTTTGACCAA TTCA TCGGTTOCATTGCATTTAATTTATGGACCACTG

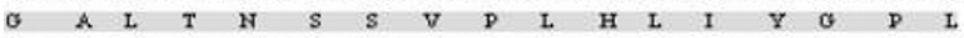
GATCCAGTCAATCCOCATCCTGAATTCTTGGATCAATACAAGAAACTTATT 90 $\begin{array}{lllllllllllllllll}D & P & V & N & P & H & P & E & F & L & D & Q & Y & K & K & I & I\end{array}$ CCCAAGTCAACCTTTACTGTACTGGATGATCACATCAGTCACTACCCTCAG 958

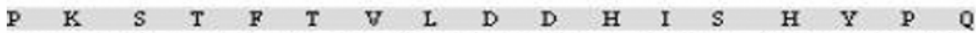
CTGGAGGACCCCACTGGATTCCTGAATGCTTATCTAAACTTTATCAATTCA 1009

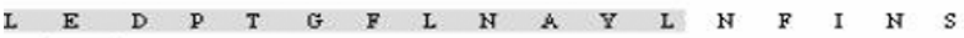
TTTTGAGCCACAAAGAACAAGTTAATTTGGTGTCTATTTCATTCTGTGTGA 1060 F

ATATGGAGCTCTGTTAAAGCAATAACAAGTTTAAGTAAAGTTTTCTACACA ATGGGCTCCTGACTTGCTCTGGACTAAAACACCAGCAGTGAOCCCAGCCAG ACATGTCTCAGGGATAGTCTTTAACACTGTATGTACCTACAATATATTTTTA ACTCACTAAGTGTTTTATGTTATTOCTGGCGTCAGTATTGGAGAAATTGCAT GTTCCGAATACAATCAGTATTTTAAAAGCAAAAAAAAAAAAAAAAAAAAA AAAAAAAAA

Fig. 1 Mest gene nucleotide and deduced amino acid sequence of Bufo gargarizans Nucleotides are numbered up and deduced amino acids are below. ATG: initiation codon; TAG: termination codon.

(Georgiades et al, 2001; Edwards et al, 2007). In the researches of huamn and mouse, imprinted role of Mest gene was related to the methylation of $\mathrm{C}_{\mathrm{P}} \mathrm{G}$ island (Reule et al, 1998; Kosaki et al, 2000). However, unlike the $\mathrm{C}_{\mathrm{P}} \mathrm{G}$ island of normal and biallelically expressed genes, the $\mathrm{C}_{\mathrm{P}} \mathrm{G}$ island of Mest is exclusively unmethylated on the expressed paternal allele, but fully methylated on the silenced maternal allele (Reule et al, 1998). In human and mouse, Mest gene was expressed in amnion, brain, heart, lung, stomach, kidney and liver. Mammalian Mest gene is widely expressed throughout the embryo, mostly in mesodermal tissues (Reule et al, 1998; Kosaki et al, 2000). In our study, the Mest gene was also expressed in testis, ovary, liver, kidney, spleen, brain, stomach and lung of the adult B. gargarizans. And there is high similarity of the protein sequences and evolutionary 


\begin{tabular}{|c|c|}
\hline Xenopus & ----------------MKE"hNIQVGLLTVPFLAWL \\
\hline Bufo & 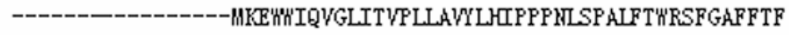 \\
\hline Gallus & --MKE"Wh'VQVGLLSVPLLWLITPPPLSPALSWKASGG---- \\
\hline Macaca & --MRE"WW'VQVGLLAVPLLHYLLIPPPQLSPALKS"KSSGKFFTY \\
\hline Homo & 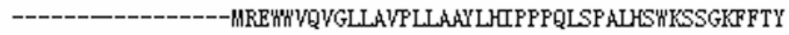 \\
\hline Mus & 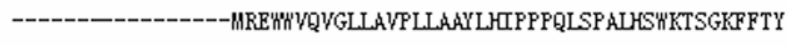 \\
\hline Danio & 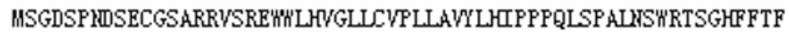 \\
\hline Taki fugu & 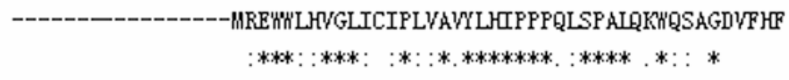 \\
\hline Xenopus & KEQQIFYRDS"GAVGSSDVIILHGFPTSSYD"WYKI"'EGLTQRFHRVIALDFIGFGFSDK \\
\hline Bufo & QEQHCFYRESWGAVGSDVIILHGFPTSSYD"YKI"WELTQRFQRVIALDFIGFGFSDK \\
\hline Gallus & --------1FKGLRGR-----YLG--PKKS----LLLLLTQRFHRVIALDFVGFGFSDK \\
\hline Macaca & KGLRIFYQDSVGWGSPEIVVLLHGFPTSSYD"WKI"'KGLTLRFHRVIALDFLGFGFSDK \\
\hline Homo & KGLRIFYQDSVGVGSPEIVVLLHGFPTSSYD"WKI"'EGLTLRFHRVIALDFLGFGFSDK \\
\hline Mus & KGLRIFYQDSVGVYGSEIVVLLHGFPTSSYDWYKI"'KGLTLRFHRVIALDFLGFGFSDK \\
\hline Danio & RGMDIFYKESVGWGSSDVLVLLHGFPTSSYDWYKI"WDLTQRFYRVIALDFLGFGFSDK \\
\hline Taki & 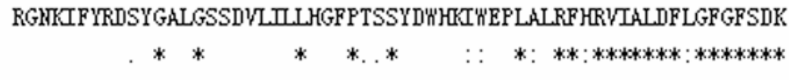 \\
\hline Xenopus & PRLHRYSIFEQASIVEAMIGHLGLRDQK/RLISHWYGDTV/AQELLFRMNRRKGGIIIGS \\
\hline Bufo & PRFHRYSIFEQASIVEALISHLGLTDQKVILLSHWYGDTVARELLYRYEHQRQGKCKIGS \\
\hline Gallus & PRPHFYSIFEQASIVERLVRLGLHFQRIKLISHYYGDTVAQELLVRYRKRKTGSILIYS \\
\hline Macaca & PRPHFYSIFEQASIVEALLRLGLQRRRIKLISHWYGDTVAQELLYRTKQYRSGRLTIKS \\
\hline Homo & PRPHHYSIFEQASIVEALLRHLGLQYRRIKLISHWYGDIVAQELLYRTKQYRSGRLTIKS \\
\hline Mus & PRPHQYSIFEQASIVESLLRLGLQRRRIKLISHWYGDIVAQELLYRYKOKRSGRLTIYS \\
\hline Danio & PRPYRYSIFEQASWVALVAHLGLSEQRIKILSHWYGDTVALELLYRSDHRRSGKIIVIS \\
\hline Tak & 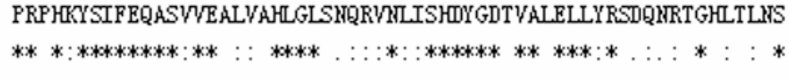 \\
\hline Xenopus & LCLSHGGFPETHYPRFIQKULWGGIFSPILTRLMYFYFFTKGISEYFGPHTQPSEAEY \\
\hline Bufo & LCLSHGGFFETHHPRLIQKULKDGGIFSPILTRLMYFYFFSKGIGEVFGPYTQPSDTEY \\
\hline Gallus & LCLSHGGFFETYYPRFIQKVLKDGGLLSPIITRLMYFFFFSRGLGAVFGPYTQPSQAEY \\
\hline Macaca & LCLSHGGTFETHRPLLLRKLKDGGVSPILTRLMYFVFSRGLTPVFGPYTRPSESEL \\
\hline Homo & LCLSHGGIFPETHRPLLLQKULKDGGVSPILTRLMYFFVFSRGLTPVFGPYTRPSESEL \\
\hline Mus & LCLSHGGFPETHRPLLLQKULKDGGVSPILTRLMYFFVFSRGLTPVFGPYTRPTESEL \\
\hline Danio & LCLSHGGIFPETHHPRFLQKVLKDSGFISPVLTRLMYFQLFSRGIKEVFGPYTQPTEAEV \\
\hline Taki fugu & LCLSHGG.FPETHHPRLATLKDSSFLAPLLTRLTHFMIFQKGIGEVPGPYTQPTHADF \\
\hline & 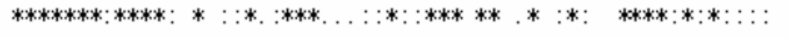 \\
\hline Xenopus & 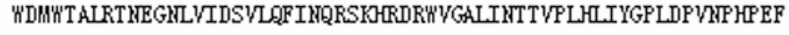 \\
\hline Bufo & 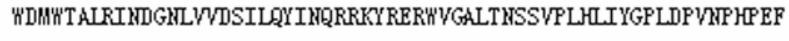 \\
\hline Gallus & 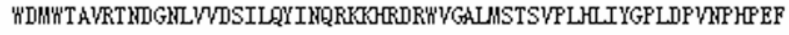 \\
\hline Macaca & 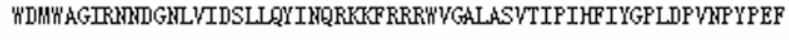 \\
\hline Homo & 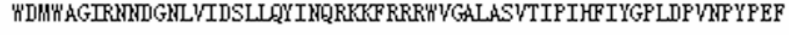 \\
\hline Mus & 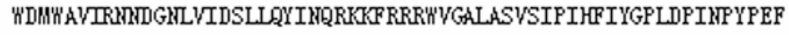 \\
\hline Danio & 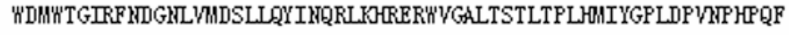 \\
\hline Taki fugu & 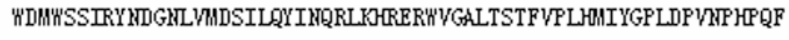 \\
\hline & 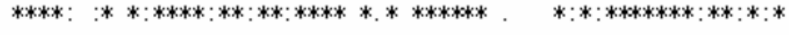 \\
\hline Xenopus & 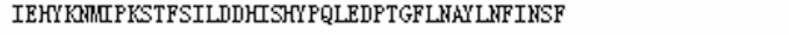 \\
\hline Bufo & LDQYKKLIPKSTFTVDDDKSHYYQLEDPTGFLHAYLYFIHSF \\
\hline Gallus & LQLYKKVLPMSTVSVLDDKCSHYPQLEDPTGFLHAYLKFINSF \\
\hline Macaca & LELYRKTLPRSTVSILDDHCSHYPQLEDPMGFLHAYMGFIHSF \\
\hline Homo & LELYRKTLPRSTVSILDDHCSHYPQLEDPMGFLHAYMGFINSF \\
\hline Mus & LELYRKTLPRSTVSILDDHSSHYQLEDPMGFLHAYMGFIYSF \\
\hline Danio & LQLYQKLVQRSTVSVLDEHVSHYPQLEDPTGFFHAYLSFIHSF \\
\hline Taki fugu & IRLYQQLVQRSTLTILDEHCSHYPQLEDPTGFLHAYFYFIHSF \\
\hline
\end{tabular}

Fig. 2 Mest amino acid alignment of the Bufo gargarizans (GenBank accession number: ABQ10905)

The identical amino acid residues are indicated $(*)$, the $\alpha / \beta$-hydrolase fold domain was boxed by straight line. Accession numbers of other vertebrates are Homo species (NP_803490), Mus musculus (AAM78507), Macaca mulatta (XP_001098320), Gallus gallus (XP_425258), Xenopus tropicalis (NP_001005789), Takifugu rubripes (CAB96533) and Danio rerio (CAK04921). 


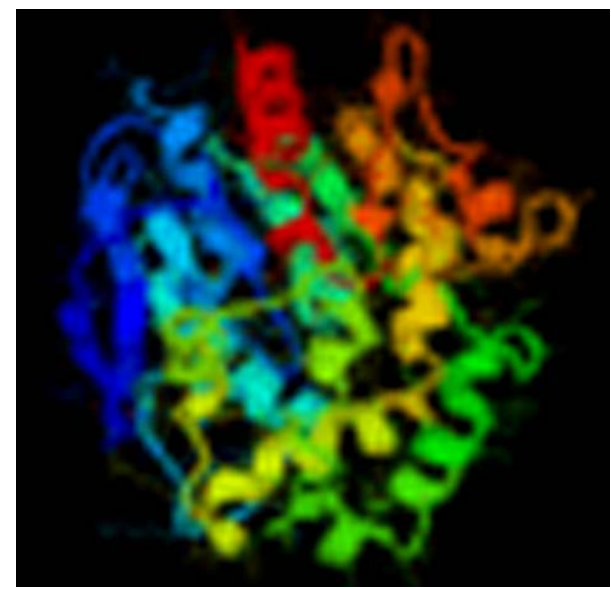

Fig. 3 3-D model of the BgMest protein conservation between BgMest and the Mest genes of other vertebrates. But according to the analysis of development and allelic expression of the zebrafish Mest, Hahn et al (2005) concluded that zebrafish Mest gene is not imprinted, at least in the larval stage. Thus, whether the genomic structure of BgMest contains a typical $\mathrm{C}_{\mathrm{P}} \mathrm{G}$ island and structure of DNA methylation needs to be further dertermined.

According to Fig. 5, the tree may indicate the evolutionary relationships of the potential imprinting genes of mammals and other vertebrates examined in the study. The classical Mendel's law of inheritance suggested that both alleles are actively transcribed and functionally equivalent. However, imprinted genes represent an exception to this rule, as they are expressed

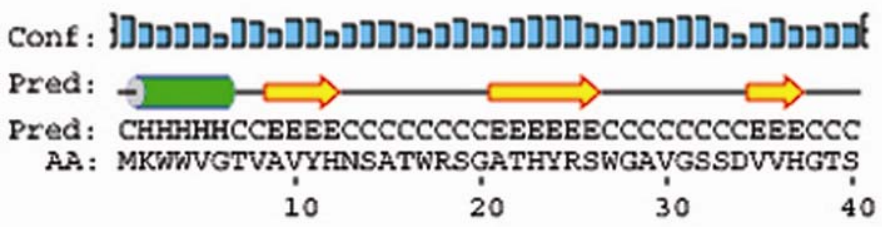

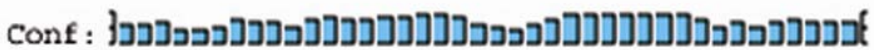

Pred

Pred: CCCCCCCCCEEEECCCCCCCCHHHHHHHHHHHHHHCCCCC

AA: SYDWYKWGTRRVADGGSDKRHRYSASVASHGTDKVNSHDY

50

60

70

80

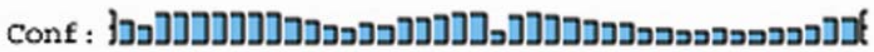

Pred:

Pred: CHHHHHHHHHCCCCCCCCCCCCCCCCCCCCHHHHEEECCC

AA: : GDTVAYRYHRGHNGSCSNGGTHHRKKDGGSTRRNYSKGGV

$90 \quad 100 \quad 110 \quad 120$

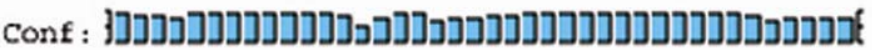

Pred: - - -

Pred: CCCHHHHHHHHHHHCCCCHHHHHHHHHHHHHHHHHHCCCC

A.A: GYTSDTYWDMWTARNDGNVVDSYNRRKYRRWVGATNSSVH

i30 i40 iso i60

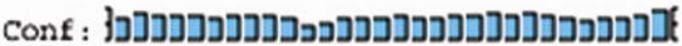

Pred:

Pred: CCCCCCCCCCCEEECCCCCCCCCCCCCCCC

AA: YGDVNHDYKKKSTTVDDHSHYDTGNAYNNS

ino iso iso

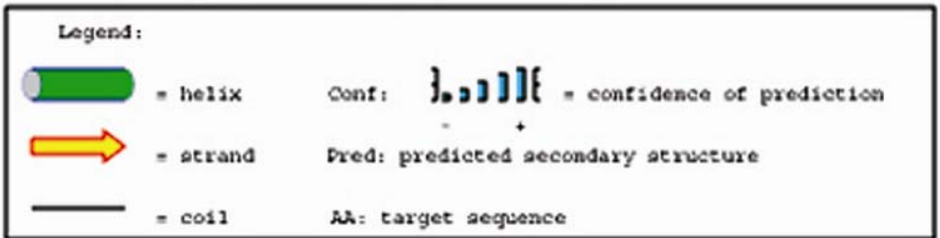

Fig. 4 Protein secondary structure of the BgMest gene 


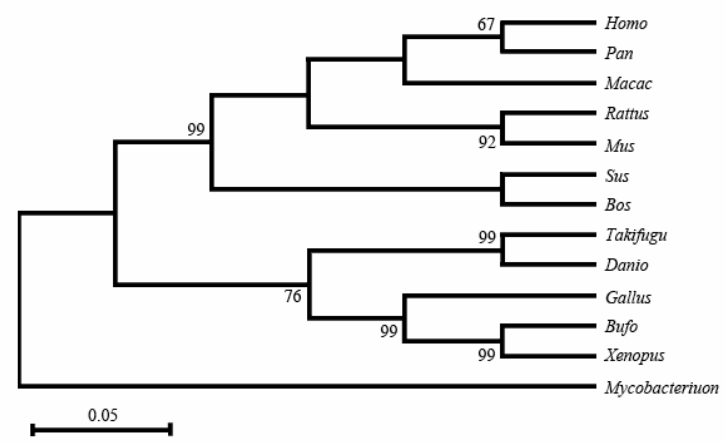

Fig. 5 Neighbour joining tree of the BgMest and Mest from other organisms based on amino acid sequence

Explanations of a part of sequences used for this tree are given in Fig. 2. Branches with less than $50 \%$ support have been collapsed. Bos taurus (Bos, AAI33640); Sus scrofa (Sus, NP_001121943); Rattus norvegicus (Rattus, NP_001009617); Pan troglodytes (Pan, XP_519382); Mycobacterium tuberculosis C (Mycobacterium, YP_002076879).

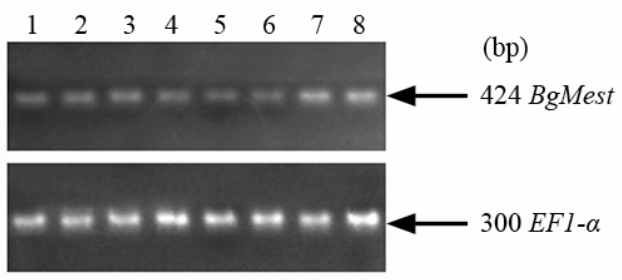

Fig. 6 RT-PCR expression of Mest in various tissues of Bufo gargarizans

1: Testis; 2: Ovary; 3: Liver; 4: Kidney; 5: Spleen; 6: Brain; 7: Stomach; 8: Lung. Mest-specific bands of $424 \mathrm{bp}$ were seen in above tissue.

from one of the two parentally inherited chromosome homologues and repressed on the other (Kaneko et al, 2002; Hou et al, 2005). The Mest genes of human and

\section{References:}

Brannan CL, Bartolomei MS. 1999. Mechanisms of genomic imprinting[J]. Curr Opin Genet Dev, 9(2): 164-70.

Charalambous M, da Rocha ST, Ferguson-Smith AC. 2007. Genomic imprinting, growth control and the allocation of nutritional resources: consequences for postnatal life[J]. Curr Opin Endocrinol Diabetes Obes, 14(1): 3-12.

Edwards CA, Rens W, Clarke O, Mungall AJ, Hore T, Marshall Graves JA, Dunham I, Ferguson-Smith AC, Ferguson-Smith MA. 2007. The evolution of imprinting:chromosomal mapping of orthologues of mammalian imprinted domains in monotreme and marsupial mammals[J]. BMC Evol Biol, 7: 157.

Georgiades P, Watkins M, Burton GJ, Ferguson-Smith AC. 2001. Roles for genomic imprinting and the zygotic genome in placental development[J]. Proc Natl Acad Sci USA, 98(8): 4522-4527.

Hahn Y, Yang SK, Chung JH. 2005. Structure and expression of the zebrafish mest gene,an ortholog of mammalian imprinted gene PEG1/MEST[J]. Biochim Biophys Acta, 1731: 125-132. mouse were considered as maternal imprinted gene, and imprinting role was for methylation of $\mathrm{C}_{\mathrm{P}} \mathrm{G}$ island (Reule et al, 1998; Kosaki et al, 2000). In mice, normal expression of Mest gene was very important for development. Knocking out and low expression of this gene may result in restraining growth and decreasing prenatal and postnatal survival (Reule et al, 1998). Nishita et al(1996)suggested that human Mest gene, the first imprinted gene to be identified on chromosome 7 , was involved in the causation of Silver-Russell syndrome (SRS) (Nishita et al, 1996). Frequent loss of imprinting of the Mest gene in humans may cause cancer tissues, such as breast cancer or lung cancer and additionally, this gene regulates placental and fetal growth (Pedersen et al, 1999; Kosaki et al, 2000; Nakanashi et al, 2004; Suzuki et al, 2005). The zebrafish Mest has been found to be biallelic expressed (Hahn et al, 2005). In addition, ASCL2/CASH4 and INS were imprinted genes in mammals, but shown biallelic expression in the chicken (Yokomine et al, 2005). In the opossum (marsupial) IGF2 and M6P were imprinted as in placental mammals, but these genes are biallelically expressed in monotremes and birds (Suzuki et al, 2005). These observations may suggest that the gene imprinting occurs in mammals except monotremes (Hahn et al, 2005). Hahn et al (2005) considered that species, or clade, specific imprinted genes may have survived the selection for diluted imprinting in the evolution of non-mammalian species. Does the BgMest gene conform to the opinion of Hahn et al (2005)? Is BgMest an imprinted gene? Further research is required to uncover the structure and function of this gene.

Hou XJ, Jiao LH, Chen X, Wang L. 2005. The effects of genomic imprinting on animal development and cloning $[\mathrm{J}]$. J Genet Genomics, 32(5): 550-554. [In Chinese].

Isles AR, Davies W, Wilkinson LS. 2006. Genomic imprinting and the social brain[J]. Philos Trans R Soc Lond B Biol Sci, 361(1476): 2229-2237.

Kamei Y, Suganami T, Kohda T, Ishino F, Yasuda K, Miura S, Ezaki O, Ogawa Y. 2007. Peg1/Mest in obese adipose tissue is expressed from the paternal allele in an isoform-specific manner[J]. FEBS Lett, 581(1): 91-6.

Kaneko KJ, Rein T, Latham K, DePamphilis ML. 2004. DNA methylation may restrict but does not determine differential gene expression at the Sgy/Tead2 locus during mouse development[J]. Mol Cell Biol, 24(5): 1968-1982.

Keverne EB, Fundele R, Narasimha M, Barton SC, Surani MA. 1996. Genomic imprinting and the differential roles of parental genomes in brain development[J]. Brain Res Dev Brain Res, 92(1): 91-100. 
Kosaki K, Kosaki R, Craigen WJ, Matsuo N. 2000. Isoform-specific imprinting of the human PEG1/MEST gene[J]. Am J Hum Genet, 66(1): 309-312.

Lefebvre L, Viville S, Barton SC, Ishino F, Surani MA. 1997. Genomic structure and parent-of-origin-specific methylation of Peg1[J]. Human Mol Genet, 6(11): 1907-1915.

Looijenga LH, Verkerk AJ, De Groot N, Hochberg AA, Oosterhuis JW. 1997. H19 in normal development and neoplasia[J]. Mol Reprod Dev, 46(3): 419-439.

Mezquita J, Mezquita PM. 1997. Characterization and expression of two chicken cDNAs encoding ubiqutin fused to ribosomal protein of 52 and 80 amino acids[J]. Gene, 195: 313-319.

Nishita Y, Yoshida I, Sado T, Takagi N. 1996. Genomic imprinting and chromosomal localization of the human MEST gene[J]. Genomics, 36: 539-542.

Nakanashi H, Suda T, Katoh M, Watanabe A, Igishi T, Kodani M, Matsumoto S, Nukamoto M, Shigeoka Y, Okabe T, Oshimura M, Shimizu E. 2004. Loss of imprinting of PEG1/MEST in lung cancer cell lines[J]. Oncol Rep, 12(6): 1273-1278.

Pedersen JS, Dervan PA, Broderick D, Harrison M, Miller N, Delany F, O' Shea D, Costello P, McGoldrick A, Keating G, Tobin B, Gorey T, McCann A. 1999. Frequent loss of imprinting of PEG1/MEST in invasive breast cancer[J]. Cancer Res, 59(21): 5449-5451.

Pedersen JS, Dervan P, McGddrick A, Harrison M, Ponchel F, Speirs V,
Isaacs JD, Gorey T, McCann A. 2002. Promoter switch: a novel mechanism causing biallelic PEG1/MEST expression in invasive breast cancer[J]. Hum Mol Genet, 11(12): 1449-1453.

Reule M, Krause R, Hemberger M, Fundele R. 1998. Analysis of Peg1/Mest imprinting in the mouse[J]. Dev Genes Evol, 208(3): 161-163.

Saitoh S, Wada T. 2000. Parent-of-origin specific histone acetylation and reactivation of a key imprinted gene locus in Prader-Willi syndrome[J]. Am J Hum Genet, 66(6): 1958-1962.

Scott RJ, Spielman M. 2004. Epigenetics: imprinting in plants and mammals-The same but different?[J]. Curr Biol, 14: 201-203.

Suzuki S, Renfree MB, Pask AJ, Shaw G, Kobayashi S, Ishino TK, Ishino F. 2005. Genomic imprinting of IGF2, p57(KIP2) and PEG1/MEST in a marsupial, the tammar wallaby[J]. Mech Dev, 122: 213-222.

Yokomine T, Shirohzu H, Pubowasito W, Toyoda A, Iwama H, Ikeo K, Hori T, Mizuno S, Tsudzuki M, Matsuda Y, Hattori M, Sakaki Y, Sakaki H. 2005. Structural and functional analysis of a $0.5-\mathrm{Mb}$ chicken region orthologous to the imprinted mammalian Asc12/Mash2-lgf2-H19 region[J]. Genome Res, 15: 154-165.

Zai Y, Qu XH, Zhou GQ, He FC. 2002. Cloning and tissue expression of the novel human differentiation-related gene Ndr2[J]. Chn J Biochem Mol Biol, 18(2): 139-144.[In Chinese]. 